\title{
Sexually communicable micro-organisms in human semen samples to be used for artificial insemination by donor
}

\author{
K H TJIAM,* B Y M VAN HEIJST, $\dagger$ A A POLAK-VOGELZANG $\ddagger$ PH H ROTHBARTH, $\S$ Th VAN \\ JOOST,* E STOLZ,* AND M F MICHEL $\dagger$ \\ From the Departments of ${ }^{*}$ Dermatovenereology, and + Clinical Microbiology and Antimicrobial Therapy, \\ Erasmus University, Rotterdam, the $¥$ National Institute of Public Health and Environmental Hygiene, \\ Bilthoven, and the §Department of Clinical Virology, University Hospital, Rotterdam, the Netherlands
}

SUMMARY Two hundred and thirty seven semen samples from 10 institutes for artifical insemination by donor (AID) in Belgium and the Netherlands were tested for the presence of Neisseria gonorrhoeae, Chlamydia trachomatis, Mycoplasma hominis, Ureaplasma urealyticum, herpes simplex virus, and cytomegalovirus. The incidence of these micro-organisms in the semen samples was $0 \%, 6 \cdot 3 \%, 4.6 \%, 35.9 \%, 0 \%$, and $0.4 \%$ respectively, and $47 \%$ of all samples were infected with one or more of the micro-organisms. As the ejaculates from which the samples had been taken had already been, or would be, used for AID, the exclusion of microbiological contamination with sexually communicable micro-organisms before insemination is indicated.

\section{Introduction}

Artificial insemination by donor (AID) is used thousands of times a year in the Netherlands and Belgium in cases of male infertility. In general, microbiological examination of the semen samples before insemination is incomplete, especially as fresh semen is often used. In view of the epidemic incidence of sexually communicable diseases it would seem to be important that semen samples intended for AID should be subjected to such tests as are necessary to prevent iatrogenic infections in women. For this reason a study was set up in Rotterdam, the Netherlands, to investigate the incidence of Neisseria gonorrhoeae, Chlamydia trachomatis, Mycoplasma hominis, Ureaplasma urealyticum, herpes simplex virus (HSV), and cytomegalovirus (CMV) in frozen semen samples that had been or would be used for AID.

Address for reprints: $\operatorname{Dr} \mathrm{K} H$ Tjiam, Department of Dermatovenereology, University Hospital, Dr Molewaterplein 40, 3015 GD Rotterdam, the Netherlands

Accepted for publication 28 June 1986

\section{Materials and methods}

SEMEN SAMPLES

Two hundred and thirty seven semen samples frozen at $-196^{\circ} \mathrm{C}$, from ten AID institutes in the Netherlands and Belgium were supplied in $0.25 \mathrm{ml}$ or $0.5 \mathrm{ml}$ straws. The semen had been given voluntarily by donors, who received a small sum for expenses. The samples were all diluted $2: 1$ or $1: 1$ with a cryoprotective liquid containing glycerol and sometimes also egg yolk or bovine serum albumin. Fifty samples contained ampicillin $380 \mathrm{mg} / \mathrm{l}$ and 36 contained kanamycin $5 \mathrm{mg} / \mathrm{l}$. Forty samples came from an institution that used only fresh semen. The semen was diluted 1:1 with Eagle's modified minimum essential medium (EMEM) with $15 \%$ fetal calf serum, and was frozen to $-196^{\circ} \mathrm{C}$. Volumes of $120-200 \mu$ l were diluted with $2 \mathrm{ml}$ of EMEM for culture for $N$ gonorhoeae, $C$ trachomatis, HSV, and CMV. Volumes of 60-200 $\mu \mathrm{l}$ were suspended in $2 \mathrm{ml}$ of U-9 medium ${ }^{1}$ for culture for $M$ hominis and $U$ urealyticum.

\section{CULTURE METHODS}

\section{Culture for $\boldsymbol{N}$ gonorrhoeae}

Semen diluted with EMEM was inoculated with a loop on to a medium consisting of GC medium base (Difco), haemoglobin (Difco), and IsoVitalex (BBL), and was incubated for $\mathbf{4 8}$ hours. 


\section{Culture for $C$ trachomatis}

A $200 \mu$ l volume of semen diluted with EMEM was again diluted 1:1 with EMEM. A $200 \mu$ l volume of each dilution was inoculated in duplicate wells on a HeLa 229 monolayer that had been rinsed with $30 \mathrm{mg} /$ 1 diethylaminoethanol (DEAE) dextran and grown in a 96 well microtitre plate (Falcon 3070). After being centrifuged for one hour at $3000 \times g$ the inoculum was replaced by $100 \mu \mathrm{l}$ EMEM with $4.5 \mathrm{mmol} / 1$ glucose, $5 \%$ fetal calf serum, $15 \mathrm{mg} / \mathrm{l}$ nystatin, $25 \mathrm{mg} / \mathrm{l}$ gentamicin, and $25 \mathrm{mg} / 1$ vancomycin. After being incubated for 48 hours at $37^{\circ} \mathrm{C}$ the monolayers were screened for the presence of inclusions after being stained with fluorescent monoclonal antibodies (Syva).

\section{Culture for HSV and CMV}

A $200 \mu$ l volume of the sample diluted with EMEM was put in a Leighton tube in which an HEL cell monolayer had been grown. Inoculation was carried out in duplicate. After being incubated for one hour at $37^{\circ} \mathrm{C}$ the inoculum was replaced by $1.5 \mathrm{ml}$ of Dulbecco's MEM with $2 \%$ fetal calf serum. The medium was renewed every week. After three weeks the cells were transferred to new tubes. The cell culture was maintained for six weeks. If there was a cytopathogenic effect the monolayer was stained with virus specific fluorescent monoclonal antibodies (MA Bioproducts).

\section{Culture for $M$ hominis and $U$ urealyticum}

The medium of Chanock et $^{\mathrm{al}} \mathrm{l}^{1}$ was used for culture for mycoplasmas. Yeast extract was prepared as described by Hers and Masurel, ${ }^{2}$ and inactivated horse serum was applied. U-9 and A-7 media ${ }^{34}$ were used for culture for ureaplasmas. Ureaplasmas were detected by the phenol red colouring in the U-9 medium and the typical colony form shown by microscopic examination of the A-7 plate. Mycoplasmas were recognised by the colony form on Chanock's medium, and further identified by the indirect immunofluorescence test of unfixed colonies. ${ }^{5}$

\section{Results}

Neither gonococci nor HSV were cultivated from any of the 237 samples. The prevalence of $C$ trachomatis, $M$ hominis, $U$ urealyticum, and CMV was $6.3 \%$, $4.6 \%, 35.9 \%$, and $0.4 \%$ respectively (table). Of the 237 samples, $112(47 \cdot 3 \%)$ were infected with one or more of the micro-organisms studied, $15(6.3 \%)$ being infected with two or three micro-organisms. The microbiological screening of the semen samples carried out by the institutes and the upper limit of leukocytes accepted varied widely. Six institutes did not perform any microbiological test on their samples. None of the institutes cultured for HSV or CMV.
TABLE Culture results in 237 semen samples

\begin{tabular}{lc}
\hline Micro-organism & No (\%) positive \\
\hline Chlamydia trachomatis & $15(6 \cdot 3)$ \\
Mycoplasma hominis & $11(4 \cdot 6)$ \\
Ureaplasma urealyticum & $85(35 \cdot 9)$ \\
Cytomegalovirus & $1(0 \cdot 4)$ \\
None & $142(59 \cdot 9)$ \\
\hline
\end{tabular}

All cultures for Neisseria gonorrhoeae and herpes simples virus were negative.

Though two institutes examined semen for ureaplasmas and mycoplasmas, some samples were nevertheless found to be infected with these microorganisms. Two of 50 samples containing ampicillin yielded chlamydiae. Eleven out of 36 specimens containing kanamycin yielded mycoplasmas or ureaplasmas. Two of the 10 institutes examined donors' urine for sediment.

\section{Discussion}

Micro-organisms were found to be present in $47 \%$ of the 237 semen samples intended for AID. This percentage is probably an underestimate. The quantity of semen $(120-200 \mu l)$ that could be extracted from the straws varied fairly widely. Moreover, the samples had to be diluted to avoid a cytotoxic effect on the cell lines used. On the other hand, however, a decrease in the concentration of semen components that inhibit growth may enhance the recovery of chlamydiae. ${ }^{6}$ The presence of kanamycin and ampicillin in 86 specimens tested would have inhibited the growth of gonococci, chlamydiae, mycoplasmas, and ureaplasmas.

The examinations carried out by the institutes are not sufficient to rule out the presence of these microorganisms in the semen they use. The only way for the institutions to ensure that the samples they obtain are free of pathogens is for them to carry out the necessary examinations of donors and semen samples. The presence or absence of micro-organisms does not seem to be related to other properties of semen, such as motility, abnormal morphology, and leucospermia. ${ }^{78}$ Neither do physical and simple laboratory examinations of donors provide conclusive evidence, as infection with sexually transmissible organisms is often symptomless.

In view of the large yearly number of inseminations carried out, it is notable that few reports of genital infections in the recipients of AID have been published. Gonococcal and ureaplasmal infections transmitted through AID have, however, been described..$^{910}$ Moreover, gonococci, chlamydiae, and other bacteria, including $\beta$-haemolytic streptococci, have been reported to survive freezing (Jordan GW et $a l$, unpublished observation). ${ }^{11-13}$ The incidence of the 
other bacteria was not investigated in this study, nor was the incidence of hepatitis B or human immunodeficiency virus (HIV). The occurrence of infections with HIV through AID has, been described, however, ${ }^{14}$ and serological examination of donors for both of these viruses is therefore indicated.

It is not known whether the contaminated semen samples have caused infections in the recipients, nor is it clear whether the presence of the micro-organisms is of pathogenic importance. That would be assessed by investigating the number and serotype of the microorganism in question and the condition of the recipients' defence mechanisms. The importance of $C$ trachomatis as a pathogenic agent in urethritis, cervicitis, salpingitis, neonatal conjunctivitis, and pneumonitis, however, has been well documented. ${ }^{15}$ $\boldsymbol{M}$ hominis is associated with salpingitis, pyelonephritis, and postpartum fever, and $U$ urealyticum can be associated with chorioamnionitis and possibly low birth weight. ${ }^{16}$ One of the causes of the "TORCHES" syndrome in neonates is congenital infection with CMV.

The results of this screening therefore point to the need to examine both the donor and the semen before insemination to avoid contamination with pathogenic micro-organisms. This implies that only frozen semen samples should be used for AID purposes.

We thank Mrs LPC Harkes for her secretarial help, and Mr R Reygers for his technical assistance.

\section{References}

1. Chanock RM, Hayflick L, Barile MF. Growth on artificial medium of an agent associated with atypical pneumonia and its identificatioin as PPLO. Pro Natl Acad Sci 1962;48:41-6.

2. Hers JFPh, Masurel N. Infection with Mycoplasma pneumonia in civilians in the Netherlands. Ann NY Acad Sci 1967;143:447-55.
3. Shepard MC, Lunceford CD. Urease color test medium U-9 for the detection and identification of " $T$ " mycoplasmas in clinical material. Applied Microbiology 1970;20:539-43.

4. Shepard MC, Lunceford CD. Differential agar medium (A-7) for identification of Ureaplasma urealyticum (Human $T$ mycoplasmas) in primary cultures of clinical material. J Clin Microbiol 1976;3:613-25.

5. Rosendal S, Black FT. Direct and indirect immunofluorescence of unfixed and fixed Mycoplasma colonies. Acta Pathol Microbiol Scand [B] 1972;80:615-22.

6. Mårdh P-A, Colleen S, Sylwan J. Inhibitory effect on the formation of chlamydial inclusions in McCoy cells by seminal fluid and some of its components. Investigative Urology 1980; 17:510-3.

7. Witkin SS, Toth A. Relationship between genital tract infections, sperm antibodies in seminal fluid, and infertility. Fertil Steril 1983;40:805-8.

8. Berger RE, Karp LE, Williamson RA, Koehler J, Moore DE, Holmes KK. The relationship of pyospermia and seminal fluid bacteriology to sperm function as reflected in the sperm penetration assay. Fertil Steril 1982;37:557-64.

9. Fiumara NJ. Transmission of gonorrhoea by artificial insemination. British Journal of Venereal Diseases 1972;48:308-9.

10. Barwin BN. Transmission of Ureaplasma urealyticum by artificial insemination by donor. Fertil Steril1984;41:326-7.

11. Sherman JK, Rosenfeld J. Importance of frozen-stored human semen in the spread of gonorrhea. Fertil Steril 1975;26: 1043-7.

12. Jennings RT, Dixon RE, Nettles JB. The risks and prevention of Neisseria gonorrhoeae transfer in fresh ejaculate donor insemination. Fertil Steril 1977;28:554-6.

13. Garcia A, Sierra MF, Friberg J. Survival of bacteria after freezing of human semen in liquid nitrogen. Fertil Steril 1981:35:549-51.

14. Stewart GJ, Tyler JPP, Cunningham AL, et al. Transmission of human T-cell lymphotropic virus type III (HTLV-III) by artificial insemination by donor. Lancet 1985;ii:581-4.

15. Darougar S, ed. Chlamydial disease. Edinburgh: Churchill Livingstone, 1983. (British Medical Bulletin. Vol 39. No 2.)

16. Taylor-Robinson D, McCormack WM. The genital mycoplasmas (parts 1 and 2). N Engl J Med 1980;302:100310, 1063-7. 